\title{
Cloud and surface classification using SCIAMACHY polarization measurement devices
}

\author{
W. A. Lotz, M. Vountas, T. Dinter, and J. P. Burrows \\ Institute of Environmental Physics, University of Bremen, Otto-Hahn-Allee 1, 28359 Bremen, Germany \\ Received: 19 March 2008 - Published in Atmos. Chem. Phys. Discuss.: 28 May 2008 \\ Revised: 14 January 2009 - Accepted: 15 January 2009 - Published: 18 February 2009
}

\begin{abstract}
A simple scheme has been developed to discriminate surface, sun glint and cloud properties in satellite based spectrometer data utilizing visible and near infrared information. It has been designed for the use with data measured by SCIAMACHY's (SCanning Imaging Absorption SpectroMeter for Atmospheric CHartographY) Polarization Measurement Devices (PMD) but the applicability is not strictly limited to this instrument. The scheme is governed by a set of constraints and thresholds developed by using satellite imagery and meteorological data. Classification targets are ice, water and generic clouds, sun glint and surface parameters, such as water, land, snow/ice, desert and vegetation. The validation has been done using MERIS (MEdium Resolution Imaging Spectrometer) and meteorological data from METAR (MÉTéorologique Aviation Régulière - a network for the provision of meteorological data for aviation). Qualitative validation using MERIS satellite imagery shows good agreement. However, the quantitative agreement is hampered by the heterogeneity of MERIS classifications within each SCIAMACHY PMD ground pixel. The comparison with METAR data shows good agreement. The comparison for sun glint classifications and MERIS results exhibits excellent agreement.
\end{abstract}

\section{Introduction}

Cloud, sun glint and surface classifications utilizing spaceborne measured data have a long history. The motivation for cloud and surface classifications are manifold, for example the creation of global thematic maps for civil and military use, the generation of time-series for climate studies or the derivation of correction factors and climatologies for geo-

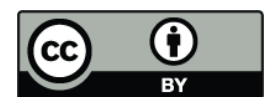

Correspondence to: W. A. Lotz (lotz@iup.physik.uni-bremen.de) physical parameter retrieval. This study is focusing on the latter issue, i.e. the use of global classified values in order to provide adequate input values especially for retrievals of atmospheric parameters.

The retrieval of atmospheric parameters can significantly be hindered by wrong input assumptions. For this reason precise cloud and surface classifications have to be derived. Some examples for affected retrievals are:

- Cloud top height retrievals of partially cloud covered ground scenes from the $\mathrm{O}_{2}$-A-band need a precise input ground albedo (Kokhanovsky et al., 2005), especially in regions, where changes from water to snow/ice surface lead to a significant increase of the surface albedo.

- Aerosol retrievals are known to be error-prone over sun glint occurrences. Therefore sun glint areas need to be flagged out of the aerosol retrievals (de Graaf and Stammes, 2005).

- Trace-gas (Buchwitz et al., 2005) and aerosol (von Hoyningen-Huene et al., 2006) retrievals are known to be very sensitive to the existence of even small fractions of clouds in the field of view need a reliable cloudflagging algorithm.

Here and in the following we consider sun glint, the specular reflection of light into the detector, also as a surface effect.

Necessary classifications for a broad set of parameters can be retrieved using satellite imagery at moderate spectral and comparatively high spatial resolution. Examples for such instruments are MERIS (MEdium Resolution Imaging Spectrometer) aboard the European Space Agency's (ESA) ENVISAT (ENVIronmental SATellite) and MODIS (MODerate resolution Imaging Spectroradiometer) which is a key instrument aboard NASA's Terra (EOS AM) and Aqua (EOS PM) satellites.

Retrievals of atmospheric trace gases often take advantage of the spectral fine structure of the absorption process in question. Among lot of very successful atmosphere satellite

Published by Copernicus Publications on behalf of the European Geosciences Union. 
Table 1. SCIAMACHY PMD channels.

\begin{tabular}{|c|c|c|c|}
\hline \multicolumn{2}{|c|}{ Channel } & \multicolumn{2}{|c|}{ Range (nm) } \\
\hline 1 & & 310 & 365 \\
\hline 2 & & 455 & 515 \\
\hline 3 & & 610 & 690 \\
\hline 4 & & 800 & 900 \\
\hline 5 & NIR & 1500 & 1635 \\
\hline 6 & & 2280 & 2400 \\
\hline 7 & $45^{\circ}$ & 800 & 900 \\
\hline
\end{tabular}

missions within the last decade the SCanning Imaging Absorption SpectroMeter for Atmospheric CHartographY (SCIAMACHY, as MERIS installed aboard ENVISAT) is one of the outstanding instruments whose primary objective is the global measurement of trace gases in the troposphere and stratosphere. However, the spatial resolution is low compared to an imager such as MERIS or MODIS.

This study aims to analyze the feasibility to classify clouds and surfaces utilizing solely measurements from the atmospheric sensor, such as SCIAMACHY. In principle a multisensor approach using for example MERIS classifications with SCIAMACHY retrievals is possible. However, failures or missing imagery data are propagating into the analysis of the atmospheric sensor. Yet another problem is the enormous amount of imagery data to be gridded to match the low spatial resolution of the atmospheric sensor which is a very time consuming computational step. The approach presented here is therefore intentionally set up as an "autonomous" one: only SCIAMACHY data are involved to classify the geophysical parameters in question. We therefore have developed a set of algorithms and constraints to have an independent, fast and simple approach. Yet another advantage is that the spectral as well as spatial sensitivity of the classification is compatible to the sensitivity of the retrieval of the atmospheric parameters.

In this study satellite imagery is used primarily to validate SCIAMACHY classifications and secondarily for the adjustment of the algorithms. As clouds or sun glint ${ }^{1}$ are highly variable spatio-temporal objects a close temporal coincidence between SCIAMACHY-based classifications and those of the imagers must be ensured. Since MERIS is located on the same platform and has basically the same measurement geometry as SCIAMACHY (in nadir mode) synchronism between both data sets is ensured. On the other hand, SCIAMACHY and MERIS sensitivities for surfaces and clouds are likely to be different due to significant deviation in spatial and spectral resolutions.

The paper is organized as follows, first we will briefly explain some technical background information about the sensors SCIAMACHY and MERIS used within this study. In the

\footnotetext{
1 and to less extend some surfaces as snow and ice
}

next section we will explain the algorithms used and finally show comparisons with independent data.

\section{Instruments}

\subsection{SCIAMACHY}

The SCanning Imaging Absorption spectroMeter for Atmospheric CHartographY, SCIAMACHY, is a passive hyper spectral UV/VIS/NIR grating spectrometer (Bovensmann et al., 1999). It was launched on-board the ENVISAT satellite in March 2002 into a polar sun-synchronous orbit, crossing the Equator on its descending node (i.e. southwards) at 10:00 a.m. local time. The instrument covers the solar radiation transmitted, backscattered and reflected from the atmosphere at relatively high spectral resolution $(0.2 \mathrm{~nm}$ to 1.5 $\mathrm{nm}$ ). It records data in eight separate main channels (noncontinuously), over the spectral range $240 \mathrm{~nm}$ to $2380 \mathrm{~nm}$, and in selected regions between $2.0 \mu \mathrm{m}$ and $2.4 \mu \mathrm{m}$. The nominal spatial resolution in nadir viewing geometry, however, is comparatively poor being $60 \mathrm{~km} \times 30 \mathrm{~km}$. The swath width of SCIAMACHY is $960 \mathrm{~km}$.

From its orbit, SCIAMACHY can observe the Earth from three distinct viewing geometries nadir, limb and lunar/solar occultation. In this study only nadir measurements are used.

Beside the main channels, also called science channels, there are seven additionally broadband detectors which measure the polarization of the incoming light. These Polarization Measurement Devices (PMD) (see Table 1) cover the spectral range of the science channels ( 2 to 6 and 8 ) and are provided to apply corrections to the polarization sensitivity of the science channels. The PMDs are mainly sensitive to parallel polarized light (parallel to the instrument slit), while the science channels measure sensitive to both polarization components. Information on the polarization of the incoming light is therefore obtained by combining the two measurements.

The PMDs are read out at $40 \mathrm{~Hz}$, but are down-sampled to $32 \mathrm{~Hz}$ for processing. This still gives a spatial resolution of $\sim 7 \mathrm{~km} \times 30 \mathrm{~km}$ which is better compared to the science channels, where the fastest read-out occurs at $8 \mathrm{~Hz}$, but more commonly at $1 \mathrm{~Hz}$. Therefore, the advantage of working with PMD data is that information is given at higher spatial resolution and it is used as sub-pixel information for the much larger SCIAMACHY measurements based on science spectra (see for example Loyola, 1998).

\subsection{MERIS}

The MEdium Resolution Imaging Spectrometer (MERIS) aboard of ENVISAT provides 15 spectral bands, which are programmable in position, width and gain. In practice, these technical characteristics are kept constant most of the time.

Measurements are performed in the $390 \mathrm{~nm}$ to $1040 \mathrm{~nm}$ spectral range (see Table 2) with an average channel width 
of about $10 \mathrm{~nm}$. MERIS is a "push-broom" spectrometer and has a $68.5^{\circ}$ field of view around nadir. The swath width of $1150 \mathrm{~km}$ is slightly larger than SCIAMACHY's. The instrument acquires data in Reduced Resolution mode (RR) and Full Resolution mode (FR). The spatial resolution is about $1.1 \mathrm{~km}$ in RR mode and $300 \mathrm{~m}$ in FR mode. We focus in this study on data in RR mode due to a broad availability of the data.

\section{Algorithms}

We developed a suite of algorithms and constraints which we called SPICS (ㄷCIAMACHY-PMD based Identification and

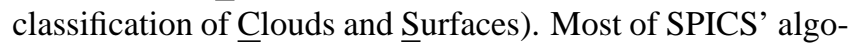
rithms utilize ratios of two PMD radiance values, the PMD reflectance value for a wavelength $\lambda$ and derived values. The PMD reflectance $R(\lambda)$ for a wavelength $\lambda$ is defined as:

$$
R(\lambda)=\frac{I(\lambda)}{I_{0}(\lambda) \cdot \mu_{0}}
$$

where $I$ is the PMD radiance value, $I_{0}$ is the PMD solar irradiance and $\mu_{0}$ is the cosine of the solar zenith angle.

The radiance values of $\mathrm{PMD}_{2}, \mathrm{PMD}_{3}$ and $\mathrm{PMD}_{4}$ are used to define a brightness component $\mathcal{B}$ as the (scaled) average of the three selected PMD reflectances $\left(R_{2}, R_{3}, R_{4}\right)$ :

$\mathcal{B}=\operatorname{av}\left(R_{2}, R_{3}, R_{4}\right) * \mathcal{S}$

For convenience the factor $\mathcal{S}$ scales the values of $\mathcal{B}$ from 0 up to 100 . Infrequent occurrences of brightness values larger 100 have been clipped. A similar concept for cloud/snow/ice-discrimination has been applied successfully by Krijger et al. (2005). The wavelength ranges associated with $\mathrm{PMD}_{2,3,4}$ can be considered as pseudo colors: blue, green and red, respectively (similar to the approach of Loyola (1998)). $\mathrm{PMD}_{1}$ is not taken into account because of the high signal values compared with $\mathrm{PMD}_{2,3,4}$.

In order to determine the range between the individual reflectance values the quantity $\mathcal{R}$ is used. We defined $\mathcal{R}$ as the range of the three PMD reflectances normalized to the average value:

$\mathcal{R}=\frac{\max \left(R_{2}, R_{3}, R_{4}\right)-\min \left(R_{2}, R_{3}, R_{4}\right)}{a v\left(R_{2}, R_{3}, R_{4}\right)}$

$\mathcal{R}$ is a measure of the goodness of a gray value.

A representative set of SCIAMACHY orbits have been utilized to derive the thresholds and constraints defined in Tables 3 and 4. All orbits in January 2006, April 2008 and July 2008 have been used for this purpose. The underlying data set consists of reprocessed, consolidated SCIAMACHY level-1 data (V6.03). Only data with solar zenith angle (SZA) $<85^{\circ}$ is taken into account.

SPICS is organized with respect to two classification groups: clouds and surfaces. It is capable to differentiate
Table 2. MERIS channels.

\begin{tabular}{lrr}
\hline Channel & Spectral Pos. (nm) & Width (nm) \\
\hline 1 & 412.5 & 10 \\
2 & 442.5 & 10 \\
3 & 490.0 & 10 \\
4 & 510.0 & 10 \\
5 & 560.0 & 10 \\
6 & 620.0 & 10 \\
7 & 665.0 & 10 \\
8 & 681.3 & 7.5 \\
9 & 705.0 & 10 \\
10 & 753.8 & 7.5 \\
11 & 760.6 & 3.8 \\
12 & 775.0 & 15 \\
13 & 865.0 & 20 \\
14 & 885.0 & 10 \\
15 & 900.0 & 10 \\
\hline
\end{tabular}

between six surface types: vegetation, snow/ice, desert, water, sun glint and land/soil as well as three cloud types: ice, water and generic clouds.

The methods, thresholds and constraints are described below. All results obtained were iteratively improved with respect to independent data sources such as co-located MERIS and meteorological data sources as METAR.

\subsection{Cloud phase}

Cloud phase retrieval with SCIAMACHY has been performed before using the science detectors (Accareta et al., 2004; Kokhanovsky et al., 2005). As explained, PMD classification results in a better spatial resolution.

Ice clouds, for example, appear brighter and normally whiter than water clouds when looking from space. Liquid water clouds usually let light penetrate deeper and absorption is leading to an increased level of grayness.

For one pass of the cloud classification we have to quantify the cloud grayness using Eqs. 2 and 3. In order to reliably classify a cloud phase, the value of $\mathcal{R}$ needs to be close to zero.

A well-adapted set of thresholds for $\mathcal{B}, \mathcal{R}$ and $R_{5}$ enables the classification of ice, water and generic clouds (see Table 3).

Multiple cloud classifications for one SCIAMACHY PMD ground pixel were rejected. However, cloud classification together with different surface types can be retrieved with reasonable accuracy (see next section).

\subsection{Surface classification}

Each surface classification approach is briefly explained in the following. Table 4 summarizes all applied thresholds. Simultaneous classification of surface and cloud parameters 
Table 3. Constraints for cloud type assignment.

\begin{tabular}{|c|c|c|c|c|c|c|}
\hline \multirow{2}{*}{$\begin{array}{l}\text { Parameter } \\
\text { Clouds } \\
\text { Ice cloud }\end{array}$} & \multirow{2}{*}{$\begin{array}{l}\text { Descript. } \\
\text { Bright white }\end{array}$} & \multicolumn{5}{|l|}{ Range } \\
\hline & & 70 & $\leq$ & $\mathcal{B}$ & $<$ & 100 \\
\hline & & 0.0 & $\leq$ & $\mathcal{R}$ & $<$ & 5.0 \\
\hline & & 0.050 & $\leq$ & $R_{5}$ & $<$ & 0.100 \\
\hline & White & 50 & $\leq$ & $\hat{\mathcal{B}}$ & $<$ & 80 \\
\hline & & 0 & $\leq$ & $\mathcal{R}$ & $<$ & 10.0 \\
\hline & & 0.050 & $\leq$ & $R_{5}$ & $<$ & 0.10 \\
\hline & Milk white & 30 & $\leq$ & $\mathcal{B}$ & $<$ & 60 \\
\hline & & 0.0 & $\leq$ & $\mathcal{R}$ & $<$ & 20.0 \\
\hline & & 0.050 & $\leq$ & $R_{5}$ & $<$ & 0.090 \\
\hline & Gray & 20 & $\leq$ & $\mathcal{B}$ & $<$ & 45 \\
\hline & & 0.0 & $\leq$ & $\mathcal{R}$ & $<$ & 40.0 \\
\hline & & 0.050 & $\leq$ & $R_{5}$ & $<$ & 0.090 \\
\hline \multirow[t]{12}{*}{ Water cloud } & Bright white & 70 & $\leq$ & $\mathcal{B}$ & $<$ & 100 \\
\hline & & 0.0 & $\leq$ & $\mathcal{R}$ & $<$ & 5.0 \\
\hline & & 0.100 & $\leq$ & $R_{5}$ & & \\
\hline & White & 50 & $\leq$ & $\hat{\mathcal{B}}$ & $<$ & 80 \\
\hline & & 0 & $\leq$ & $\mathcal{R}$ & $<$ & 10.0 \\
\hline & & 0.100 & $\leq$ & $R_{5}$ & & \\
\hline & Milk white & 30 & $\leq$ & $\hat{\mathcal{B}}$ & $<$ & 60 \\
\hline & & 0.0 & $\leq$ & $\mathcal{R}$ & $<$ & 20.0 \\
\hline & & 0.090 & $\leq$ & $R_{5}$ & & \\
\hline & Gray & 20 & $\leq$ & $\dot{\mathcal{B}}$ & $<$ & 45 \\
\hline & & 0.0 & $\leq$ & $\mathcal{R}$ & $<$ & 40.0 \\
\hline & & 0.090 & $\leq$ & $R_{5}$ & & \\
\hline \multirow[t]{9}{*}{ Generic cloud } & Bright white & 30 & $\leq$ & $\mathcal{B}$ & $<$ & 80 \\
\hline & & 0.0 & $\leq$ & $\mathcal{R}$ & $<$ & 5.0 \\
\hline & & 0.09 & $\leq$ & $R_{5}$ & $\leq$ & 0.17 \\
\hline & White & 30 & $\leq$ & $\dot{\mathcal{B}}$ & $<$ & 48 \\
\hline & & 3.0 & $\leq$ & $\mathcal{R}$ & $<$ & 8.0 \\
\hline & & 1.30 & $\leq$ & $R_{5}$ & $\leq$ & 1.60 \\
\hline & Gray & 30 & $\leq$ & $\mathcal{B}$ & $<$ & 60 \\
\hline & & 6.0 & $\leq$ & $\mathcal{R}$ & $<$ & 14.0 \\
\hline & & 0.65 & $\leq$ & $R_{5}$ & $\leq$ & 1.30 \\
\hline
\end{tabular}

Legend:

$\mathcal{B}$ brightness, $\mathcal{R}$ rel. range, $R_{i}$ reflectance $\mathrm{PMD}_{i}$

are possible. However, simultaneous surface classifications are not allowed.

For "vegetation" and sun glint the gray-value concept is not used. In the latter case it turned out that vegetation classification is clearly superior using a modified NDVI (Normalized Differenced Vegetation Index) approach. For vegetation we therefore define the NDVI $\mathcal{N}$ analogous:

$\mathcal{N}=\frac{R_{4}-R_{3}}{R_{4}+R_{3}}$

Applying a cutoff value of $\leq 1.18$ removes non-vegetation ground pixels reliably. However, light reflected from vegetation is able to induce a considerable polarization component
Table 4. Constraints for surface type assignment.

\begin{tabular}{|c|c|c|c|c|c|c|}
\hline $\begin{array}{l}\text { Parameter } \\
\text { Surfaces }\end{array}$ & Descript. & Range & & & & \\
\hline \multirow[t]{4}{*}{ Sun glint } & & & & $t$ & $<$ & \\
\hline & & & & $\rho_{74}$ & $<$ & 2.168 \\
\hline & & & & $R_{4}$ & $<$ & 0.0600 \\
\hline & & & & $R_{5}$ & $<$ & 0.0725 \\
\hline \multirow[t]{3}{*}{ Water } & & & & $\mathcal{B}$ & $<$ & 40 \\
\hline & & & & $\mathcal{N}$ & $<$ & 1.00 \\
\hline & & 0.000 & $\leq$ & $R_{5}$ & $<$ & 0.020 \\
\hline \multirow[t]{4}{*}{ Snow\&ice } & All except & 0.00 & $\leq$ & $\rho_{54}$ & $<$ & 0.20 \\
\hline & Antarctica & 0.0015 & $\leq$ & $R_{5}$ & $<$ & 0.0360 \\
\hline & Only & & & latc & $<$ & -60 \\
\hline & Antarctica & 0.00 & $\leq$ & $\rho_{54}$ & $<$ & 0.40 \\
\hline Vegetation & & 1.18 & $\leq$ & $\mathcal{N}$ & & \\
\hline \multirow[t]{4}{*}{ Desert } & & -60 & $\leq$ & latc & $<$ & 60 \\
\hline & & 1.670 & $\leq$ & $\rho_{54}$ & & \\
\hline & & 0.000 & $\leq$ & $\mathcal{N}$ & $<$ & 1.110 \\
\hline & & 0.110 & $\leq$ & $R_{5}$ & $<$ & 0.260 \\
\hline \multirow[t]{4}{*}{ Land } & & 20 & $\leq$ & $\mathcal{B}$ & & \\
\hline & & 25 & $\leq$ & $\mathcal{R}$ & & \\
\hline & & 1.200 & $\leq$ & $\rho_{54}$ & & \\
\hline & & 0.084 & $\leq$ & $R_{5}$ & $<$ & 0.185 \\
\hline
\end{tabular}

Legend:

$\mathcal{B}$ brightness, $\mathcal{R}$ rel. range, $\mathcal{N}$ NDVI, $t$ max. $\phi$ differ.,

$\phi$ relative azimuth, $R_{i}$ reflectance $\mathrm{PMD}_{i}, \rho_{54}$ radiance ratio $I_{5} / I_{4}$, $\rho_{74}$ radiance ratio $I_{7} / I_{4}$, latc center latitude

depending on the health state of the plant. Therefore, this modified NDVI can only be a first estimation.

"Sun glint" is specular reflection of sun light by adequately tilted facets of water into the detector. Careful analysis of glint could for example help to improve aerosol retrievals, which could otherwise be strongly affected (see de Graaf and Stammes (2005)).

Sun glint is able to exhibit a considerable degree of polarization. This can be observed when investigating SCIAMACHY's PMD signals. To uncover sun glint's polarization features we define the ratio $\rho_{74}=\mathrm{PMD}_{7} / \mathrm{PMD}_{4} . \mathrm{PMD}_{7}$ and $\mathrm{PMD}_{4}$ (ATBD, 1999) are the radiance values for PMD seven and four and are primarily sensitive to Stokes vector elements $U$ and $Q$ (Coulson, 1988), respectively. Following standard text books the ratio $U / Q$ can be related to $\chi=0.5 \arctan U / Q$, which is the tilt angle of the polarization ellipsoid. Thus the ratio $\rho_{74}$ is related to $\chi$. It should be noted that for unpolarized light $U$ and $Q$ are zero, therefore $\chi$ is undefined.

Examining the ratio $\rho_{74}$ globally over three months of data a clear contrast of sun glint regions to others can be found. If the angle $\chi$ over water is larger (or equals) zero and smaller $32.6^{\circ}\left(0<\rho_{74}<2.168\right)$ sun glint can be classified 


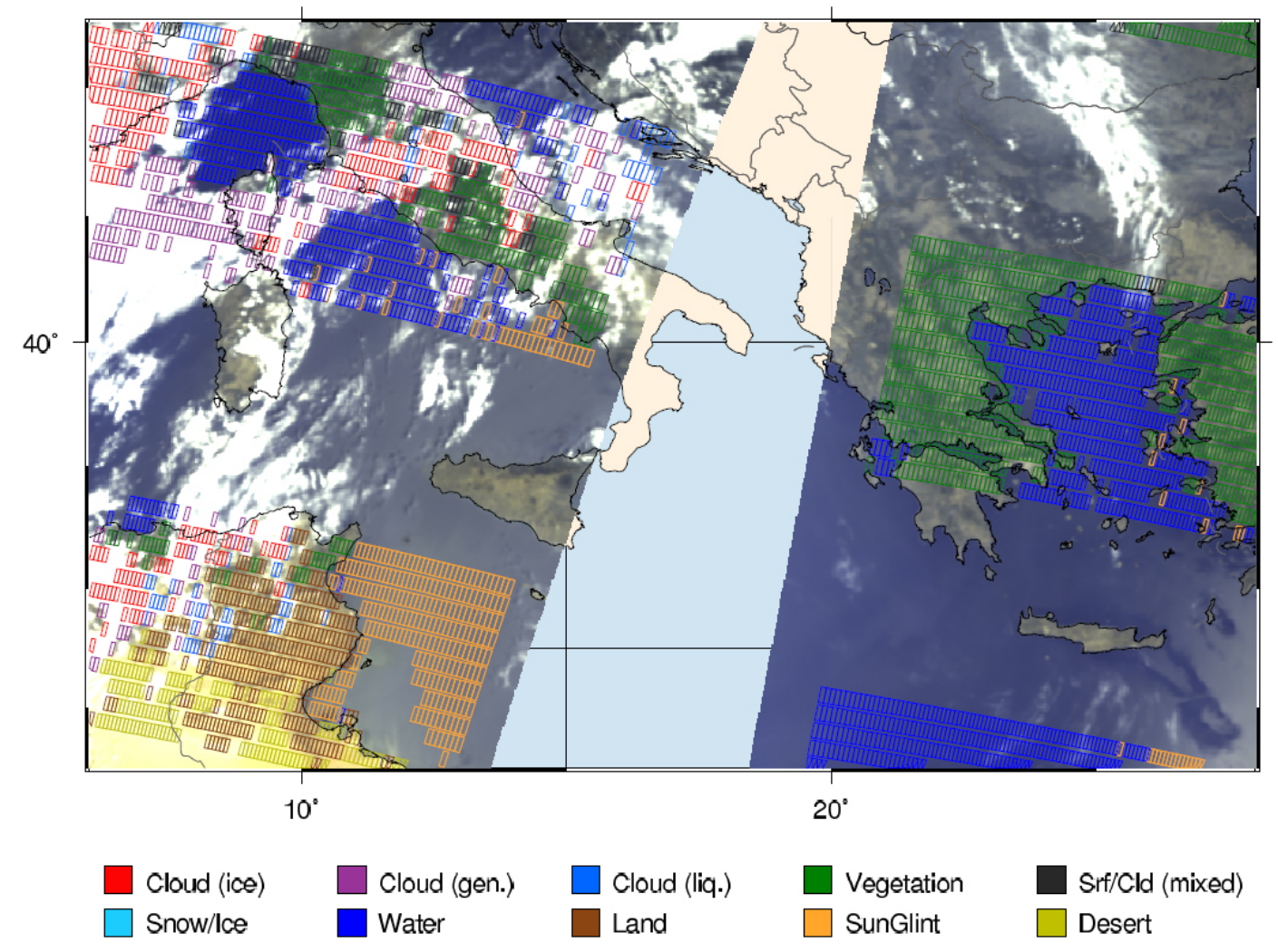

Fig. 1. Classification for the central Mediterranean Sea.

reliably. Without limitation to water this approach would also detect sun glint over various desert regions due to increased amounts of polarization of the reflected light - and therefore a well-defined value $\chi$. The water-land discrimination procedure is using the radiance ratio from $\mathrm{PMD}_{5}$ and $\mathrm{PMD}_{4}$ providing the necessary contrast between land and water. The threshold intervals to eliminate land pixels can be found in Table 4. Please note, that the water-land discrimination is not strongly affected by changing the threshold limits. This enables also occasional detections over land which can be identified as lakes, wetlands or flood plains.

The last test is to ensure proper geometrical conditions: an absolute value of an azimuth difference of $40^{\circ}$ between line-of-sight and sun position may not be exceeded (same condition seen in Qin et al. (2006)). As mineral dust aerosols contribute to the depolarization of the detected light and the ratio $U / Q$ lies within a limit where significant polarization is expected, no substantial impact of (desert) aerosols is observed. In Fig. 1 sun glint detections are shown for the central Mediterranean.

Note, that the quality of the ratio $U / Q$ from SCIAMACHY PMD measurements was under discussion (Krijger and Tilstra, 2003; Schuttgens et al., 2004). The background of the discussion is that the PMDs provide essential input for the Polarization Correction Algorithm (PCA) of SCIAMACHY. For the PCA the requirements regarding the ac- curacy of the PMD measurements are comparatively high. However, the approach presented here is not affected - as the ratio $\rho_{74}$ or the angle $\chi$ is not needed as an absolute value.

"Liquid water" classification can be an important issue for several other retrievals where the derivation of a geophysical parameter is either hampered, like for instance in case of the retrieval of $\mathrm{CO}, \mathrm{CH}_{4}$ (Buchwitz et al., 2005) or only possible like in case of chlorophyll concentration (Vountas et al., 2007). The thresholds used for the classifications where derived on the base of comparison with a large amount of MERIS-pixels. We found that $\mathcal{B}$ (as defined in Eq. 3) must be smaller 40, indicating a low level of brightness (obviously, as water appears blue in the visible). Since water reflects (for both polarizations) very poorly in the near infrared $R_{5}$ will be low. A reliable threshold for water pixels is $R_{5}<0.020$.

The "Snow/ice" classification is based on the radiance ratio for PMD five to four, $\rho_{54}$, as already proposed by Krijger et al. (2005). However, we adjusted the thresholds to the daily updated AMSR-E sea ice maps (see SeaIce (2008)) and derived slightly different thresholds and an additional constraint. We propose that the radiance ratio should be within the following interval: $0 \leq \rho_{54}<0.2$ where the reflectance $R_{5}$ should be $0.0015 \leq R_{5}<0.036$.

"Desert" classification is also based on the radiance ratio for PMD five to four, $\rho_{54}$. Comparisons with data from the "global land cover 2000 project" (Global Land 
Cover, JRC, 2000) showed that $\rho_{54}$ should be larger or equal 1.67 indicating that both channels exhibit a sufficient contrast over desert. In order to distinguish clouds over desert the reflectance for PMD five must be: $0.110 \leq R_{5}<0.245$. Desert classification, however, has been limited to a corridor between $\pm 60^{\circ}$ in order to avoid having mismatches with snow/ice classifications over Antarctica.

"Land/soil" classification is based on $\mathcal{R}$ which must be smaller or equal 25 , the ground scene will have to be more grayish than in case of water classifications. An additional constraint using $R_{5}$ ensures reliable classification of land pixels: $0.084 \leq R_{5}<0.185$.

\section{Validation}

The analysis of classifications of vegetation, water and land (soil or desert) is comparatively trivial when comparing with true or pseudo-true color imagery. Sun glint is a rapidly changing parameter over the orbit but can also be identified very easily through visual analysis. This holds for the cloud detection using SPICS. As MERIS measures the same scene at the same time as SCIAMACHY it is straightforward to use it for the comparisons. As a first qualitative test we have prepared pseudo- RGB (red/green/blue) images using eight channels of MERIS in reduced resolution $(1.1 \mathrm{~km} \times 1.1 \mathrm{~km})$. SPICS classifications were overlayed the MERIS pseudoRGB for several scenes and showed good agreement. Exemplarily Fig. 1 shows two orbits of two consecutive days (21 and 22 August 2007) over central Mediterranean Sea. The classifications are in good agreement with the underlying MERIS image. Broken clouds near Italy as well as large cloud formations in the west are well represented. Water and land classifications for the eastern orbit over cloudfree Greece and the Aegean Sea are reproducing the actual MERIS scene reliably. The transition from vegetation to soil and desert over Tunisia is also well classified. Furthermore the clear Land/Vegetation and Sun glint contrast classified by SPICS at the east coast of Tunisia is obviously reproducing the actual conditions during the measurement represented by MERIS' RGB imagery. Gaps with missing classifications are due to inadequate threshold intervals. They are more frequent in regions of partial or complete cloud coverage, as can be seen in some regions of the western orbit.

A first attempt was made to further validate the discrimination of general cloud and ice cloud classification in the next section.

\subsection{Cloud phase classification}

As explained above SPICS allows the discrimination of cloud types. The types can roughly be classified as ice clouds, water clouds and generic clouds. The latter includes those which were classified as clouds but the phase discrimination could not be performed.
In order to a make a first step towards a validation we compared SPICS' cloud type classification with results of MERIS level 2 data. MERIS cloud type products (Meris Products specifications, 2007) are available at reduced spatial resolution of about $1.1 \mathrm{~km} \times 1.1 \mathrm{~km}$. To use this data within SCIAMACHY's field of view their results must be gridded. MERIS provides basically nine cloud types which we have re-classified to family A, B and C clouds.

- Family A: high clouds with large amount of ice crystal (Cirrus, Cirrostratus and deep convection).

- Family B: middle clouds. Mainly water clouds frequently containing super cooled droplets, as well as small amounts of ice crystals (Altocummulus, Altostratus, Nimbostratus).

- Family C: low water clouds (Cummulus, Stratocummulus, Stratus)

The comparison was performed over one set of SCIAMACHY measurements in South-East Europe. Figure 2a shows the results for SPICS, Fig. 2b MERIS cloud family classifications which have been gridded to SCIAMACHY PMD ground pixel sizes and Fig. $2 \mathrm{c}$ a full resolution true color image of MERIS for improved visualization which was provided by ESA via web front-end (unfortunately no full resolution level 2 data were available). In some cases the gridding of MERIS classifications to create Fig. $2 b$ led to multiple cloud family detections within one SCIAMACHY PMD ground pixel. In such cases we selected the predominant family by taking the classification providing at least $2 / 3$ of the whole amount of pixels gridded.

For clarity both figures (Fig. 2a and b) show only cloud (phase) classifications, simultaneous surface classifications are not shown. Good qualitative agreement between SPICS ice and water cloud classifications with MERIS family A, B and $\mathrm{C}$ cloud classifications can be found. Both figures also reveal strengths and weaknesses: SPICS is capable to detect even optically thin clouds (especially near river Dniester at about $26^{\circ}$ longitude $/ 48^{\circ}$ latitude) where MERIS did not detect clouds. However, MERIS is able to detect comparatively small clouds due to its high spatial resolution (for example, at Danube Delta, over Black Sea and near Crimea). When comparing with the (pseudo-) true color image of MERIS (Fig. 2c) in full resolution the frazzled and whitish-thin appearance of a lot of clouds within this scene give reason to suspect that cirrus clouds are involved. However, neither MERIS nor SPICS classifications could proof this for the ground pixels in question.

To elaborate the classifications quantitatively the validation will be extended to the comparison involving thermal infrared measurements in a future study. Here, data of AATSR (Advanced Along-Track Scanning Radiometer) aboard ENVISAT will be utilized in order to be able to discriminate cloud phase information more reliable (Kokhanovsky et al., 2006). 
a)

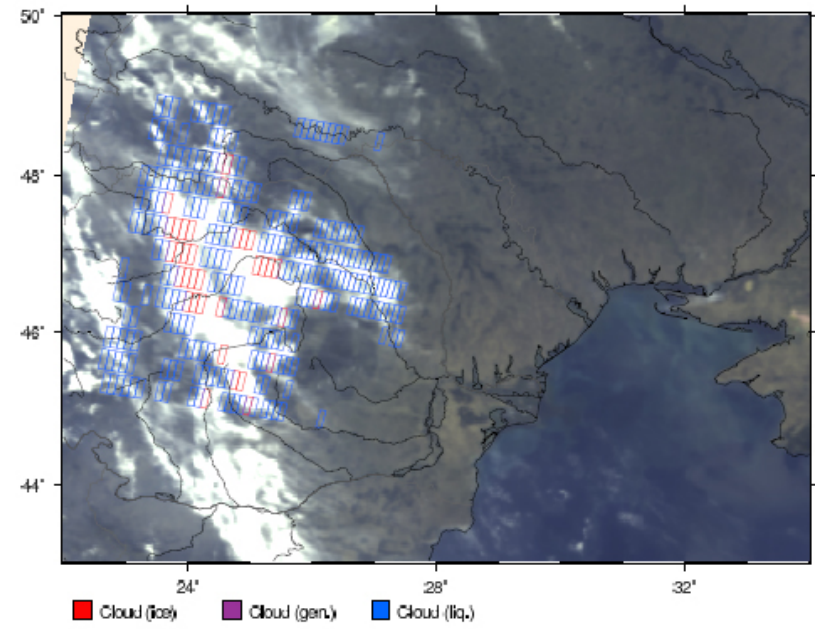

b)

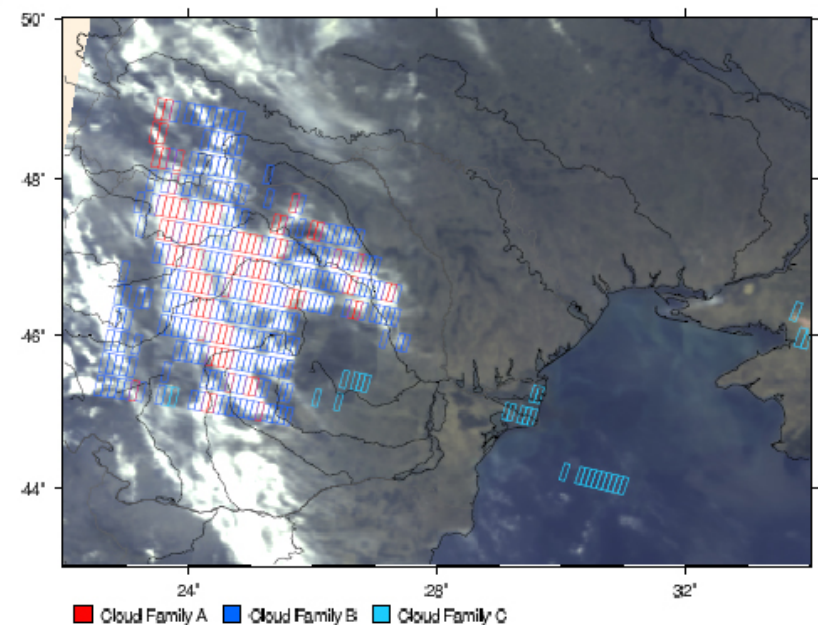

c)

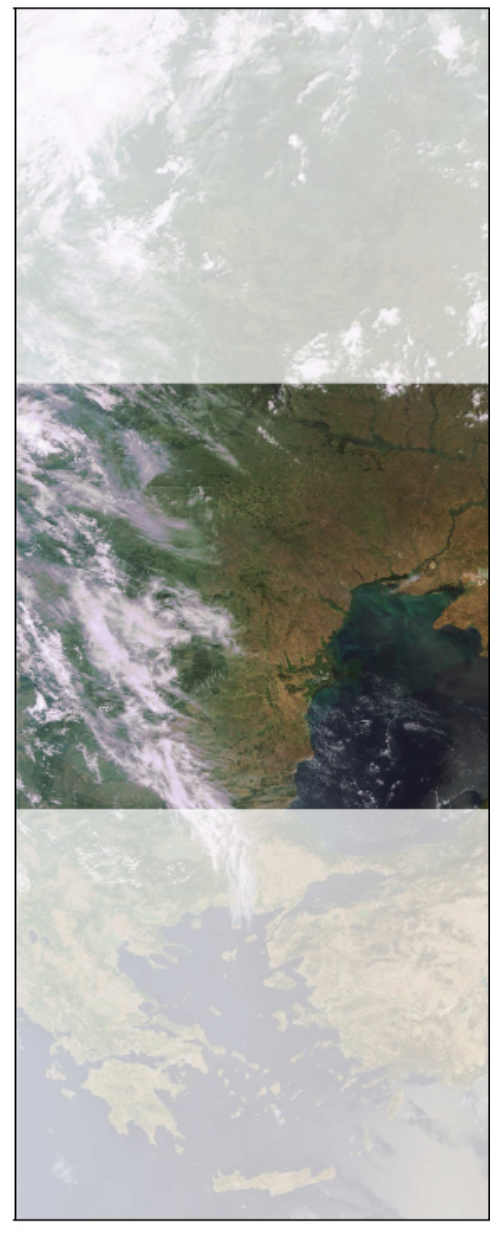

Fig. 2. Cloud classification for Southeast Europe and Black Sea. (a) Cloud classifications from SPICS with underlying MERIS true color image with low spatial resolution; (b) MERIS results after classifications into three altitude families and gridding (see text); (c) MERIS full resolution true color image of the (highlighted) regions of interest.

\subsection{Quantitative Validation using MERIS}

To validate SPICS classifications on a global scale, MERIS level 2 data were used again for obvious reasons. MERIS classifications for water, land and clouds are available from level 2 data at reduced spatial resolution. The simultaneous MERIS classifications for 22 August 2007 were matched to SCIAMACHY ground pixel size and location. Here, MERIS classifications were gridded to SCIAMACHY PMD size and location. Typically more than 150 MERIS classifications could be gridded to one SCIAMACHY PMD ground pixel. Among the individual MERIS classifications the number of occurrences were stored. More than 460 million MERIS pixels were gridded to over 2.3 million SCIAMACHY PMD ground pixels. Multiple classifications for one ground pixel are possible for both data sets, however, for different reasons: while SPICS classifies different surface or cloud properties through the exploitation of a set of thresholds related to dif- ferent spectral or polarization sensitivities of SCIAMACHY, MERIS is capable to deliver multiple classifications at SCIAMACHY's sub-pixel level.

Related to the total amount (2295 124) of SCIAMACHY PMD ground pixels $35.04 \%$ of all water classifications using SPICS could be matched to MERIS (absolute number of matches and mismatches can be found in Table 5). $41.59 \%$ of all land classifications and $16.42 \%$ of all cloud classifications from SPICS could be matched to MERIS. As a result 93.05\% of all values could be matched to MERIS and $6.95 \%$ of all values could not be matched to MERIS in any of the three classes. 3\% of all values contain no SPICS classification and are included in the amount of mismatches.

This analysis was based on the requirement that at least 130 (2/3 of possible) MERIS values of one classification needed to be gridded into one SCIAMACHY PMD ground pixel.

If we reduce the above requirement to 100 MERIS values with identical classification gridded into one SCIAMACHY 
Table 5. SPICS and MERIS matches and mismatches.

\begin{tabular}{lll}
\hline Classification & Matched & mismatched \\
\hline water & 804313 & 63812 \\
land & 954463 & 72463 \\
cloud & 376770 & 23303 \\
\hline
\end{tabular}

PMD ground pixel the amount of mismatches increases to $13.22 \%$. Relaxing this constraint to 75 MERIS pixels increases the number of mismatches to $16.1 \%$. This indicates that the mismatches are due to the significant difference in the spatial resolution.

Moreover, this behavior reveals a potential weakness of the comparison: while classifications using SPICS are based on broadly spatially averaged spectral information, MERIS classifications were based on spectral information averaged over a much smaller area. Compared to cloud classifications water/land mismatches are relatively frequent due to the inability of SPICS to detect small coverage of water/land within one SCIAMACHY PMD ground pixel, i.e. in the vicinity of bright cloud fields, small patches of water and land are outshone.

"Cloud phases": the same methodology has been used to validate the cloud phase classifications. The above described SCIAMACHY data set has been classified also with respect to cloud phases and compared with MERIS data which consisted out of the three altitude layers A, B and C (as defined in Sect. 4.1). The preliminary results are still not satisfactory. We found more matches for lower than for higher clouds. Poor agreement, however, was found for clouds of altitude type B. With respect to the reasonable results of the visual analysis this was surprising. The reasons for this could be:

- the approach comparing MERIS cloud types for altitude layers A, B and C could not simply be transferred to SPICS cloud classifications.

- SPICS could (yet) not be capable to discriminate cloud types with good accuracy due to limited capabilities of the threshold method.

- the quality of the MERIS classifications might not be sufficient.

A further analysis using additional and independent data sources needs to clarify the situation. As already explained (see Sect. 4.1) such a comparison could involve data of AATSR.

"Sun glint": for the validation of sun glint we use the same scenario as described at top of this subsection. Used are now the two sun glint flags as part of the MERIS reduced resolution cloud dataset. First MERIS flag is calculated accounting only for geometry aspects. The second MERIS flag takes additionally wind speed into account and therefore includes effects of surface roughness.
In all cases (more than 135000 SCIAMACHY PMD pixels) where SPICS classified a ground pixel as Sun glint affected both MERIS sun glint flags were switched on. To switch on MERIS sun glint flags at least 130 MERIS values (ca. $2 / 3$ of possible values) needed to be gridded to one SCIAMACHY ground pixel. This excellent result shows that the developed approach is valid, simple and feasible using SCIAMACHY PMD data.

\subsection{Comparisons with METAR data}

METAR delivers relevant meteorological data for aviation. However, the data are useful also for the validation of SPICS - especially for regions of mixed snow/ice and clouds. Hourly data of 72 METAR (airport based) measurement stations were collected over ten months which resulted into a complete data set with more than 440000 records. Colocated station data sets were compared with SPICS classifications.

In order to validate SPICS potential to discriminate snow/ice and clouds we start the analysis using two METAR stations and co-located MERIS measurements. Two METAR stations on Greenland have been selected: Kulusuk Lufthavn (METAR station code: BGKK) and Constable Pynt (METAR station code: BGCO). Classifications have been computed for SCIAMACHY orbit 29423. Two consecutive MERIS scans have been overlayed the data set to provide additional pseudo-true color information (see Fig. 3).

Station BGKK reports complete overcast during SCIAMACHY and MERIS measurements with a horizontal visibility larger than $1 \mathrm{~km}$ and a surface temperature of 0 degree Celsius. The reported cloud bottom height was $1.2 \mathrm{~km}$. From preceding and succeeding orbits, as well as meteorological METAR data we found that the headland where the station is located was snow-clad. This has also been the case for station BGCO. BGCO, however, reports clear sky during over-flight of ENVISAT with a visibility larger than $10 \mathrm{~km}$ and a surface temperature of -8 degrees Celsius (14:50 UTC).

The observations reported are in agreement with SPICS' classification: snow classifications are determined for BGCO station and vicinity whereas cloud classifications agree with the reports from BGKK. Underlying MERIS pseudo-true color images support that the snow and cloud classifications generally worked well but the visual discrimination based on MERIS imagery remains difficult in the vicinity of the two stations. However, the underlying MERIS pseudo-true color images are useful for the western part of the measurement cycle near BGKK station. Here the imagery shows a large field of clouds over ice which exhibits a clear (textural) contrast to the surrounding ice field. There are also numerous failed classifications in these regions where the classification thresholds are not adequate and have still to be improved further.

To evaluate the quality of SPICS results more generally we have extended the comparison to all stations but for 


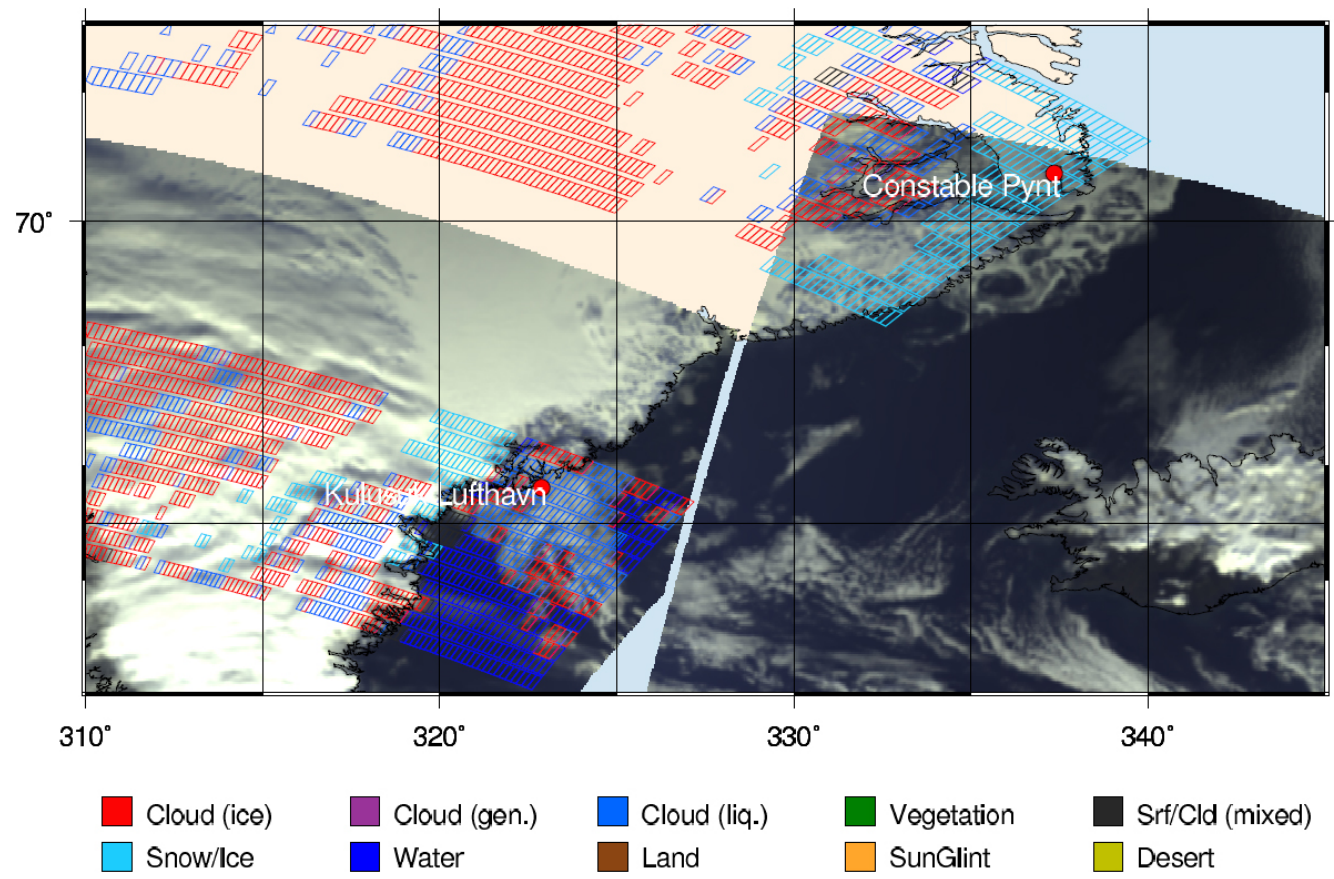

Fig. 3. Classification for Greenland for 16 October 2007 (start time of the SCIAMACHY Orbit 29423 was 14:10 UTC).

simplicity reasons without considering MERIS data. Colocations were defined within a circle with $6 \mathrm{~km}$ radius around the center coordinates of the station which had to include the PMD's center coordinates and with a maximum temporal difference of $15 \mathrm{~min}$. As common for aviation data METAR's cloud fraction is given in two oktas and refer either to a measured or human-observed quantity within the visual horizon.

54 co-locations met the requirements. Analyzing the data set carefully revealed that 46 SPICS classifications were in agreement with METAR. The following results were obtained:

- in 33 cases SPICS classified the SCIAMACHY pixel as cloudy and METAR reports for the corresponding colocation at least $25 \%$ cloud fraction.

- in 13 cases SPICS is able to classify the surface and METAR reports sufficiently low cloud fraction which is less or equal $25 \%$. The experience made from MERIS comparisons (see Sect. 4.2) showed that SPICS has the ability to detect the surface when a small fraction of the ground pixel is cloud covered. In four of this cases SPICS classified the surface being snow/ice covered and the meteorological databases confirmed it.

- in eight cases SPICS classifies the ground pixel as surface, but METAR reports cloud fractions larger 25\% and smaller or equal to $88 \%$. We conclude that SPICS has only limited ability to classify surfaces in the presence of larger and optically thick cloud fields. Further studies have to be performed in order to improve SPICS under these conditions.
- in no cases SPICS classified the pixel as cloudy and METAR reported complete cloud free conditions.

\section{Conclusions}

A scheme has been developed to identify and classify clouds and surfaces which we have called SPICS: SCIAMACHYPMD based Identification and classification of Clouds and Surfaces. It is based on SCIAMACHY's polarization measurement device data utilizing a set of thresholds and constraints. The approach was motivated to create an independent, fast, simple and spectral as well as spatial compatible way classifying important geo-physical parameters. The quantities classified are: ice, water and generic clouds, sun glint and surface parameters, such as water, snow/ice, desert and vegetation.

The applicability is not limited to SCIAMACHY. Other instruments designed with similar concepts could benefit from the classification scheme after adapting corresponding thresholds.

The validation of SPICS results was performed against MERIS qualitatively and quantitatively. Qualitatively the comparison was successful but the quantitative analysis showed that the capability of SPICS classifying multiple characteristics (out of two groups: clouds and surfaces) was not always sufficient to reproduce the rich variability of the measured imager scene. Due to the comparatively low spatial resolution of SCIAMACHY's PMD measurements (7 km $\times 30 \mathrm{~km})$, SPICS has only limited capability to resolve sub-pixel information. If, however, the amount of homogeneity within one SCIAMACHY PMD ground pixel is 
sufficient (as rule of thumb: $\geq 2 / 3$ ), SPICS and MERIS classifications are in reasonable agreement. The mismatches of classification results observed could, however, not only be led back to the deficiencies of SCIAMACHY's spatial resolution. For example, MERIS full resolution (FR) imagery showed optically (and geometrically) thin clouds which were classified by SPICS but the MERIS classification did not detect clouds at all. However, the next step to quantify the quality of SPICS cloud discrimination capabilities needs to involve data from additional sources, such as for example AATSR.

Very promising validation results have been achieved comparing MERIS and SPICS sun glint classifications.

The validation was additionally performed against METAR (a network for the provision of meteorological aviation) data. The agreement for co-located data points was encouraging. It is planned to extend the local METAR data set in order to perform the validation on a broader spatial and temporal base and use these results to potentially improve SPICS' thresholds.

The validation to show SPICS' capability to separate clouds and snow/ice covered surfaces has been done using MERIS imagery and METAR data. First promising results for Greenland could be shown. However, the study is planned to be extended: more METAR data have to be collected to provide a large data base to ensure a sufficient amount of temporal and spatial coincidences with SPICS. Furthermore, it is planned to test the utilization of cloud fractions derived by SPICS data as sub-pixel information for SCIAMACHY science pixels.

Acknowledgements. We thank Vladimir Rozanov and Alexander Kokhanovsky for fruitful discussions about polarization issues.

Edited by: T. Wagner

\section{References}

ATBD: ENVISAT: SCIAMACHY Level 0 to 1 Processing - Algorithm Theoretical Basis Document, ENV-ATB-DLR-SCIA0041, Deutsches Zentrum für Luft- und Raumfahrt, 1999.

Acarreta, J. R., Stammes, P., and Knap, W. H.: First retrieval of cloud phase from SCIAMACHY spectra around $1.6 \mu \mathrm{m}$, Atmos. Res., 72, 89-105, 2004.

Bovensmann, H., Burrows, J. P., Buchwitz, M., Frerick, J., Noël, S., and Rozanov, V. V.: SCIAMACHY: Mission Objectives and Measurement Modes, J. Atmos. Sci., 56, 127-150, 1999.

Buchwitz, M., de Beek, R., Noel, S., Burrows, J. P., Bovensmann, H., Bremer, H., Bergamaschi, P., Kürner, S., and Heimann, M.: Carbon monoxide, methane and carbon dioxide columns retrieved from SCIAMACHY by WFM-DOAS: year 2003 initial data set, Atmos. Chem. Phys., 5, 3313-3329, 2005, http://www.atmos-chem-phys.net/5/3313/2005/.

Coulson, K. L.: Polarization and Intensity of Light in the Atmosphere, A. Deepak Publishing, 1988.

de Graaf, M. and Stammes, P.: SCIAMACHY Absorbing Aerosol Index - calibration issues and global results from 2002-2004, Atmos. Chem. Phys., 5, 2385-2394, 2005, http://www.atmos-chem-phys.net/5/2385/2005/.
Heygster, G. and J. Borgmann, Daily Updated AMSR-E Sea Ice Maps: http://iup.physik.uni-bremen.de:8084/amsr/amsre.html, 2008.

Joint Research Center: Global Land Cover 2000, Institute for Environment and Sustainability, EC, http://ies.jrc.ec.europa.eu/ global-land-cover-2000, 2000.

Kokhanovsky, A. A., Rozanov, V. V., Burrows, J. P., Eichmann, K.-U., Lotz, W., and M. Vountas: The SCIAMACHY cloud products: Algorithms and examples from ENVISAT, Adv. Space Res., 36(5), 789-799, 2005.

Kokhanovsky, A. A.: Microphysical and optical properties of noctilucent clouds, Earth-Sci. Rev., 71, 127-146, 2005.

Kokhanovsky, A. A., Jourdan, O., and Burrows, J. P.: The Cloud Phase Discrimination from a Satellite, IEEE Geosc. and Rem. Sens. Let., 3, 103-106, 2006.

Krijger, J. M. and Tilstra, L. G.: Current Status of SCIAMACHY polarisation measurements, Spec. Publ. SP-531, ESA, Noordwijk, Netherlands, 2003.

Krijger, J. M., Aben, I., and Schrijver, H.: Distinction between clouds and ice/snow covered surfaces in the identification of cloud-free observations using SCIAMACHY PMDs, Atmos. Chem. Phys., 5, 2729-2738, 2005, http://www.atmos-chem-phys.net/5/2729/2005/.

Loyola, D.: A New Cloud Recognition Algorithm for Optical Sensors, IEEE International Geoscience and Remote Sensing Symposium, Seattle, WA, 572-574, 1998.

Meris Products specifications: ENVISAT Products Specifications, ESA Doc., PO-RS-MDA-GS-2009, 11, 2007.

Metar online: METAR online archive provided by National Oceanic and Atmospheric Administration (NOAA): http://weather.noaa. gov/weather/metar.shtml, 2008.

Qin, X., Li, Z., Xin, T., Yong, P., Casanova, J. L., Calle, A., Zengyuan, L., and Goldammer, J.: Forest Fire Identification using AATSR and MODIS Data, Working Progress Presentation, Santorini, Greece, 12 July 2006, 2006.

Schuttgens, N. A. J., Tilstra, L. G., and Stammes, P.: On the relationship between Stokes parameters Q and U of atmospheric ultraviolet/visible/near-infrared radiation, J. Geophys. Res., 109, D09205, doi:10.1029/2003JD004081, 2004.

Tuinder, O. N. E., de Winter-Sorkina, R., and Builtjes, P. J. H.: Retrieval methods of effective cloud cover from the GOME instrument: an intercomparison, Atmos. Chem. Phys., 4, 255-273, 2004, http://www.atmos-chem-phys.net/4/255/2004/.

Von Bargen, A., Kurosu, T., Chance, K., Loyola, D., Aberle, B., and Spurr, R.: ERS-2: Cloud Retrieval Algorithm for GOME (CRAG), Final Report, Tech. rep., German Aerospace Center (DLR) and Smithsonian Astrophysical Observatory (SAO), 2000.

von Hoyningen-Huene, W., Kokhanovsky, A. A., Burrows, J. P., Bruniquel-Pinel, V., Regner, P., and Baret, F.: Simultaneous determination of aerosol and surface chracteristics from MERIS top-of-atmosphere reflectance, Adv. Space Res., 37, 2172-2177, 2006.

Vountas, M., Dinter, T., Bracher, A., Burrows, J. P., and Sierk, B.: Spectral studies of ocean water with space-borne sensor SCIAMACHY using Differential Optical Absorption Spectroscopy (DOAS), Ocean Sci., 3, 429-440, 2007, http://www.ocean-sci.net/3/429/2007/. 